Trab. Ling. Aplic., Campinas, 44(1): 133-160, Jan./Jun. 2005

\title{
LEVANTAMENTO DE PROCESSOS EM CARTAS DE MALA DIRETA*
}

\author{
RODRIGO E. DE LIMA-LOPES \\ (Gealin-PUCSP/UNIFIEO)
}

\begin{abstract}
RESUMO
Neste trabalho, apresento um estudo sobre processos materiais (Halliday, 1994) em um corpus de 104 cartas de venda de produtos/serviços (malas diretas) escritas em português brasileiro. Meu objetivo é verificar se os diferentes movimentos e passos das cartas (Swales, 1990) possuem diferenças na distribuição dos processos e na função realizada por cada um deles. Esse estudo contou com o uso de ferramentas computacionais e de um sistema de etiquetagem manual, utilizado na recuperação dos processos através de programas de concordância (Scott, 1999; Manson, 1999). Resultados mostram que o movimento responsável pelo propósito comunicativo das cartas é o que carrega o número mais alto de processos e o sistema de escolhas mais complexo.
\end{abstract}

Palavras-chave: Gramática Sistêmico-Funcional, Sistema de Transitividade, Análise do Campo.

\section{ABSTRACT}

This piece of research aimed at analysing 104 direct sale letters (33.633 words) in Brazilian Portuguese. The corpus was explored in order to investigate the process patterns (Halliday, 1994, 1985) in the System of Transitivity (Experiential Metafunction) and its distribution over the different moves and steps (Swales, 1990). Corpus Linguistics was the main methodological tool; two software for lexical analysis (Manson, 1999; Scott, 1999) and a tagging system were used. Results show that the move responsible for the communicative purpose of the letters is the one which carries the highest number of processes and the most complex system of choices.

Key-words: Systemic-Functional Grammar, System of Transitivity, Field Analysis.

\section{INTRODUÇÃO}

O foco desta pesquisa é a análise de 104 cartas de venda, comumente chamadas de cartas de mala direta, e sua motivação está na necessidade de compreensão das relações entre linguagem e cultura, analisando sua manifestação dentro do contexto de interação. Dentre as várias possibilidades, analisarei as escolhas dos processos no sistema de transitividade (Halliday, 1994) dessas cartas, que vendem produtos e/ou serviços. Esse levantamento visa observar se os diferentes movimentos (e passos) possuem diferenças tanto na quantidade de escolhas léxico-gramaticais, como na função exercida por elas e na variação do campo do discurso, como definido por Halliday e Hasan (1989). Os processos serão estudados a partir de duas perspectivas. A primeira é quantitativa, sendo que aqui sua distribuição entre os diferentes movimentos será comparada, de forma a determinar se há

\footnotetext{
* Obrigado a Leila Barbara e Valéria Branco Moreira Pinto dos Santos por leituras prévias deste artigo.
} 
LIMA-LOPES - Levantamento de processos materiais em cartas de mala direta.

variações, e se elas, de alguma forma, contribuem para o desenvolvimento da estrutura do texto; nesta etapa todos os processos estarão sendo estudados conjuntamente. Na segunda, os materiais, que são os mais freqüentes no corpus, serão estudados de acordo com sua variação de campo, evidenciando diferenças entre os movimentos.

Isso se deu por duas razões. Em primeiro lugar, os estudos sobre gênero normalmente privilegiam o levantamento de elementos lexicais que marcam a transição entre os diferentes movimentos e que evidenciam o conteúdo ideacional e interpessoal dos textos ou, então, trabalham com a formação da imagem e sua relação com o discurso (Swales, 1990; Bhatia, 1993; Ghadessy, 1993; Santos, 1996; Van Nus, 1999; Vian Junior, 1997; Souza, 1997; Baptista, 1999 entre outros). Poucos são os trabalhos que analisam as escolhas no Sistema de Transitividade nos movimentos, observando se as diferenças de função dos movimentos geram diferenças nos padrões léxico-gramaticais. Em segundo lugar, há poucos estudos sobre o sistema de transitividade em língua portuguesa, como é o caso de Bressane (2000) e Heberle (1999) que trabalham com reuniões de negócios e editoriais de revistas femininas, respectivamente, sendo que nenhum desses trabalhos lida com o levantamento dos perfis de transitividade nos gêneros estudados, uma vez que neles a transitividade é um instrumento auxiliar.

Assim, procura-se entender as possíveis relações entre o contexto de produção das cartas, sua estrutura organizacional e as escolhas léxico-gramaticais. Logo, este trabalho orientar-se-á pela gramática sistêmico-funcional (Halliday, 1973, 1976, 1985, 1991, 1992b, 1993, 1994) e seguidores (Martin et al., 1997; Thompson, 1996; Eggins, 1994). A abordagem sistêmico-funcional dá grande importância ao contexto sócio-cultural da produção lingüística: toda a produção está atrelada às necessidades e funções sociais desempenhadas. Por conseguinte, todos os enunciados realizados são fruto da operacionalização de significados, regulados pelo contexto da cultura e da situação de forma paradigmática, dando a essa abordagem, segundo Stubbs (1996: 25), um caráter ciência social e aplicada.

É importante observar que este trabalho não tem como objetivo levantamentar os movimentos e passos das cartas. Ele parte dos resultados já encontrados em estudos anteriores (Lima-Lopes 2002, 2001), os quais utilizaram o mesmo corpus desta pesquisa. Entre outros resultados, eles determinaram a estrutura genérica das cartas aqui estudadas, além do levantamento dos movimentos obrigatórios e opcionais. Aqui, adotam-se as propostas de Swales $(1990,1991$ e 1992) para a análise de gêneros. Isso ocorreu devido à existência de vários estudos sobre cartas comerciais (Bhatia 1993a,b; Cheung, 1993 e Santos 1996) que utilizam sua proposta e que serviram como ponto de partida para esta pesquisa e para Lima-Lopes $(2003,2001)$. Utilizou-se também o auxílio de alguns teóricos em GSF, principalmente Eggins e Martin (1997), que propõem o estudo conjunto do gênero e do registro, definindo a TR\&G (Teoria do Registro e Gênero).

De forma a alcançar os objetivos propostos, o presente artigo se divide em sete seções. Na primeira serão expostos alguns conceitos sobre a Gramática-Sistêmico Funcional (doravante GSF), seguidos das descrição dos procedimentos e do corpus utilizado na pesquisa. A terceira seção traz as teorias de gênero utilizadas neste trabalho, bem como discute os estudos que determinaram a estrutura genérica aqui utilizada. Na próxima seção, 
os processos serão analizados de forma quantitativa, de forma a identificar quais movimentos (e passos) possuem maior concentração de processos, sendo analisadas as consequiências dessa distribuição, as funções desempenhadas pelos principais tipos de processos e os padrões léxico gramaticais de realização. Na próxima parte os processos materiais serão analisados segundo sua variação de campo. Cabe dizer que esse recorte ocorreu devido a sua importância; como mostrarão os resultados, os materiais são os processos mais freqüentes, sendo responsáveis por quase $70 \%$ de todos os verbos do corpus.

\section{A GSF: O SISTEMA DE TRANSITIVIDADE}

A GSF pode ser descrita como uma abordagem semântico-funcional, cuja preocupação é explorar como a língua é estruturada para o uso em diferentes contextos (Eggins, 1994: 23-24). Uma das premissas básicas dessa abordagem é que o uso da língua é motivado pelas relações sociais (Eggins, 1994: 4) e que as escolhas léxico-gramaticais realizadas pelos falantes não são aleatórias e estão condicionadas pelo contexto. Assim, uma determinada escolha pode ser influenciada ou determinada, ou ainda, influenciar ou determinar as escolhas à sua volta (Thompson, 1998: 30).

Nessa abordagem, a língua é um sistema que oferece ao falante uma série de possibilidades para expressar os seus significados. A gramática é um construto operacional que organiza as funções realizadas pelo falante; os diferentes significados possuem diferentes formas de expressão, cada uma com diferentes probabilidades de ocorrência, dadas as variações de contexto. Ao realizar um significado através de um item lexical ou um fraseado “wording”, o falante está realizando uma escolha entre outras prováveis, fazendo com que o uso da língua tenha um caráter probabilístico (Halliday, 1993, 1992a, 1991; Stubbs, 1996).

A metafunção experiencial está ligada ao uso da língua enquanto representação, estando relacionada tanto ao mundo externo, eventos, elementos, como ao mundo interno, pensamentos, crenças, sentimentos etc. A realização dessas representações ocorre através do sistema de transitividade, que pressupõe a escolha de processos (elementos verbais) e seus argumentos (Eggins: 1994, 220). Esse sistema é a nossa mais forte expressão da experiência, uma vez que o falante constrói um mundo de representações, baseado na escolha de um número tangível de tipos de processos (Halliday, 1994: 106). Dentro do sistema de transitividade, cada proposição consiste de três elementos: 1) o processo, 2) os seu(s) participante(s) e 3) as circunstâncias, que são de caráter opcional. O processo é representado por um grupo verbal, e é a ação propriamente dita, ao passo que os participantes são, normalmente, representados por grupos nominais, os quais podem realizar a ação ou serem de alguma forma afetados por ela; já as circunstâncias são representadas por grupos adverbiais e sua função é adicionar informações ao processo, como mostra o exemplo abaixo. 
LIMA-LOPES - Levantamento de processos materiais em cartas de mala direta.

\begin{tabular}{|c|c|c|c|}
\hline ...o grande terremoto & destruirá & a Califórnia & a qualquer momento \\
\hline $\begin{array}{c}\text { Participante } \\
\text { (que realiza a ação) }\end{array}$ & $\begin{array}{c}\text { Processo: } \\
\text { Material }\end{array}$ & $\begin{array}{c}\text { Participante } \\
\text { (afetado pela ação) }\end{array}$ & (afetado pela ação) \\
\hline
\end{tabular}

Para Halliday (1994; 1985), há três tipos de processos principais: material, mental, relacional e três tipos de processos que ocupam uma posição intermediária: comportamental, verbal e existencial. Esses processos podem ser definidos da seguinte forma:

1. os processos materiais representam nossa experiência no mundo exterior, ações realizadas no mundo físico; seus participantes são o Ator (que realiza ação), o Beneficiário (que é atingido por ela), a Meta (que é resultante do processo) e a Extensão (que completa o sentido do verbo). Ex.: A revista ACME [participante: Ator] traz para [processo: material] os profissionais de notícia... [participante: beneficiário];

2. os processos mentais representam experiências em nosso mundo interior (inner world), ações realizadas no mundo dos pensamentos. Seus participantes são o Experiênciador (em cuja mente o experiência se dá) e o Fenômeno (que é o elemento percebido). Ex.: Ela [participante: experienciador] duvidou [processo: mental] dos resultados trazidos pelo candidato [participante: Fenômeno];

3. os relacionais representam significados ligados à identificação, cujos participantes são o identificado e o identificador, à posse, cujos participantes são o possuidor e o possuído, e à classificação, cujos participantes são o Portador e o Atributo. Ex.: Você [participante: Portador] é [processo: relacional] um desenvolvedor de produtos ACME... [participante: Atributo];

4. os comportamentais estão na fronteira entre os materiais e os mentais, realizando ações do nosso mundo interior que são exteriorizadas; seus participantes são o Comportante e a Extensão. Ex.: ...você [participante: Comportante] pode assistir [processo: comportamental] a fita... [participante: Extensão];

5. os verbais estão entre os mentais e os relacionais, trazendo relacionamentos simbólicos, construídos na consciência humana e realizados através da linguagem. Seus participantes são o Dizente, que realiza a ação e a Verbiagen, que é a mensagem em si, Ele [participante: Dizente] criticou [processo: verbal] o filme [participante: Verbiagem] avidamente...;

6. por fim, os existenciais relacionam-se a qualquer tipo de fenômeno que é reconhecido como existente; seu único participante é o existente. Ex.: Haverá [processo: existencial] caminhada, comida típica [participantes: Existentes].

Para a GSF, qualquer realização lingüística está condicionada ao contexto onde foi produzida.Para Halliday e Hasan (1989: 05), o contexto é um fator determinante na produção de um texto, assim como a situação o é em relação ao discurso nele empregado. Assim, os estudiosos da GSF estabelecem dois níveis: o contexto de situação e o contexto de cultura. 
O contexto de cultura pode ser entendido como o pano de fundo onde a interação está inserida (Halliday e Hasan, 1989), disponibilizando um potencial de realização de significados (potencial semiótico). Dessa forma, Eggins (1994) diz que o estudo do contexto de cultura envolve a observação de como a língua é estruturada para o uso. Dentro desse contexto, são estudadas as diferentes manifestações textuais, mostrando como cada uma delas se articula. $\mathrm{O}$ estudo do contexto de cultura passa pela observação e análise dos diferentes gêneros.

Já o contexto de situação (ou registro) está relacionado à situação imediata de realização do texto. Halliday (em Halliday e Hasan, 1989) define três variáveis de registro, aqui apresentadas de acordo com a reformulação de Eggins e Martin (1997: 238):

1. Campo, ou a ação social: o que acontece, a natureza da ação social, aquilo em que os falantes estão engajados;

2. Relações, ou a estrutura de papéis: quem está participando do evento e com qual função, quais são suas relações de solidariedade;

3. Modo, ou organização simbólica: qual o papel da linguagem, o que cada interactante espera da linguagem enquanto função.

Estudos sobre registro estão preocupados em observar como um texto está relacionado ao seu contexto imediato de realização. As variáveis de Modo, Relações e campo são mapeadas de forma a explicar as razões que levaram o falante a realizar determinadas escolhas, como é o caso deste estudo.

\section{CORPUS E PROCEDIMENTOS}

O corpus desta pesquisa é composto por Cartas de Venda de Produtos (CVPs) e por Cartas de Venda de Serviços (CVSs) em língua portuguesa, com um total de 33.633 palavras (tabela 1).

\begin{tabular}{|l|c|}
\hline \multicolumn{1}{|c|}{$\mathbf{N}^{\mathbf{0}}$} & Total \\
\hline Número de documentos & 104 \\
\hline Número de palavras & 33633 \\
\hline Número de palavras diferentes & 7497 \\
\hline Média palavras/cartas & 323,39 \\
\hline
\end{tabular}

Tabela 1: Composição do corpus em número de palavras

Três foram as fontes de coleta:

1. O banco de dados do projeto DIRECT, de onde foram retiradas $40 \mathrm{CVPs}$;

2. Minha correspondência pessoal (malas diretas), de onde foram retiradas $12 \mathrm{CVSs}$;

3. Correspondência pessoal e/ou profissional (malas diretas) de informantes anônimos, de onde foram retiradas 27 CVPs e 25 CVSs. 
LIMA-LOPES - Levantamento de processos materiais em cartas de mala direta.

O banco de dados do projeto DIRECT é um corpus de linguagem dos negócios com mais de dois milhões de palavras, composto por subcorpora formados por vários tipos de texto. Os informantes anônimos são indivíduos de meu contato pessoal que cederam sua correspondência particular e/ou profissional. Esses informantes selecionaram as cartas a serem cedidas e colocaram restrições à divulgação de seu nome ou nome da empresa para a qual trabalhavam. Isso levou ao apagamento de todos os nomes de indivíduos e da substituição sistemática de todos os nomes de empresa pela expressão regular ACME+Tipo de empresa.

A análise do sistema de transitividade foi realizada de forma a observar diferenças e semelhanças nas escolhas processuais nas cartas que vendem diferentes tipos de produtos/ serviços. Os processos e seus participantes foram analisados qualitativamente e quantitativamente, de forma a verificar se as escolhas variavam de acordo com o campo do discurso e o movimento.

A metodologia adotada foi a Lingüística de Corpus (McEnery e Wilson, 1996; Sinclair, 1994; Biber et al., 1999, Kennedy, 1999; entre outros), sendo que esta pesquisa contou com o uso de duas ferramentas computacionais de análise lexical (Manson, 1999; Scott, 1999), além de um sistema de marcação textual ${ }^{1}$, desenvolvido e aplicado manualmente ${ }^{2}$ (ver Lima-Lopes 2001; 2003).

O WordSmith Tools (Scott, 1999) e o Qwick (Manson, 1999) são programas que englobam várias ferramentas. Nessa pesquisa, utilizei a ferramenta de concordância, que permite a observação de uma ou mais palavras dentro do seu contexto de ocorrência, sendo que o horizonte de estudo é definido pelo pesquisador, utilizando o próprio corpus informatizado, sem listas prévias.

Os dois programas de concordância foram utilizados de forma a levantar essas anotações referentes a cada elemento do sistema de transitividade: ao invés de pesquisar por palavras ou expressões, utilizei os programas para recuperar cada tipo de processo estudado e seus participantes.

Um exemplo desse tipo de levantamento pode ser observado na figura a seguir ${ }^{3}$.

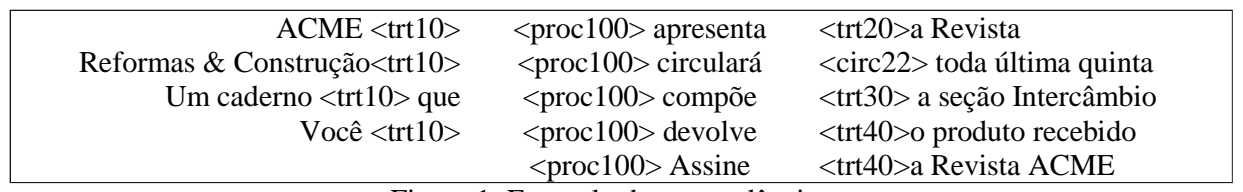

Figura 1: Exemplo de concordância

\footnotetext{
${ }^{1}$ De acordo com McEnery e Wilson (1996: 24) um corpus pode ser ou não anotado. No caso dos anotados, os corpora são complementados com uma série de informações lingüísticas que, antes, estariam implicitamente presentes, dependendo, portanto, do nosso conhecimento lingüístico para sua interpretação. Isso torna o texto um repositório de informações lingüísticas, facilitando o trabalho do analista.

${ }^{2}$ A anotação pode ser realizada por programas computacionais (automática), de forma manual (pelo pesquisador), utilizada neste estudo, ou interativa/ semi-automática (pelo pesquisador com o auxílio da máquina)

${ }^{3}$ A relação de todos os códigos para formação dessas etiquetas está disponível no Anexo A.
} 


\section{ESTRUTURA GENÉRICA}

Como já colocado anteriormente, a estrutura genérica utilizada neste trabalho, parte dos resultados obtidos por Lima-Lopes $(2001,2003)$. Nesses trabalhos, parto da proposta de gênero definida por Swales (1990).

Swales (1990) busca a compreensão dos padrões organizacionais e retóricos responsáveis pela realização prática de um discurso. Dentro do estabelecido pelo autor, é possível entender gêneros do discurso como elementos textuais de interação utilizados por uma comunidade discursiva. Esses gêneros têm como base para sua produção um propósito comunicativo, sendo que o falante também leva em consideração elementos como públicoalvo, restrições relativas à forma e nomenclatura. Logo, um gênero teria características organizacionais bem definidas, tornando possível a realização de interações que, no escopo de uma comunidade discursiva, teriam um propósito discursivo.

Esse conceito de gênero definido por Swales é usado por uma série de estudos sobre cartas comerciais (Bhatia 1993a, b; Cheung, 1993 e Santos 1996), os quais apresentam uma estrutura genérica muito similar às encontradas no corpus analisado em Lima-Lopes (2001, 2002), motivando a utilização de seus resultados como ponto de partida para a determinação da estrutura genérica.

A Estrutura Genérica das cartas analisadas é trazida pela tabela 1 (retirado de LimaLopes, 2002: 04):

\begin{tabular}{|c|c|c|}
\hline Movimentos/Passos & Total & Total \% \\
\hline Estabelecimento das relações & 96 & 92,31 \\
\hline Chamado & 33 & 31,37 \\
\hline Saudação & 78 & 75,49 \\
\hline Referências (ref.:) & 8 & 7,84 \\
\hline Credenciais da Empresa & 27 & 25,49 \\
\hline Oferta & 104 & 100 \\
\hline Introdução da oferta & 75 & 71,57 \\
\hline Detalhamento da oferta & 104 & 100 \\
\hline Valor & 34 & 33,33 \\
\hline Incentivos & 31 & 30,39 \\
\hline Demanda de ações & 96 & 92,31 \\
\hline Documentos anexos & 29 & 28,43 \\
\hline Finalização & 94 & 92,16 \\
\hline
\end{tabular}

Tabela 1: Movimentos e passos das cartas e sua frequiência relativa no corpus $\mathrm{N}=104$

(negrito=movimentos, itálico $=$ passos $)$

A figura 1 acima traz a porcentagem de ocorrência de cada um dos movimentos e seus passos no corpus de estudo. O levantamento da organização textual das cartas foi 
LIMA-LOPES - Levantamento de processos materiais em cartas de mala direta.

realizado manualmente, e cada um dos documentos teve sua organização comparada com os demais. Entre os resultados mais importantes, observa-se que:

1. $100 \%$ das cartas possuem uma descrição do que é anunciado;

2. 92,31\% das cartas possuem algum tipo de saudação inicial;

3. 92,31\% das cartas possuem alguma forma de demanda, cujo alvo é o destinatário;

4. $92,16 \%$ das cartas possuem algum tipo de fechamento;

5. $28,43 \%$ das cartas fazem referências a documentos anexos e

6. 25,49\% das cartas possuem algum tipo de descrição da empresa remetente.

Esses números sugerem que quatro podem ser os movimentos obrigatórios: a) oferta, b) estabelecimento das relações, c) finalização e d) demanda de ações, assim como dois opcionais: a) documentos anexos e b) credenciais da empresa.

O movimento que abre as cartas é estabelecimento de relações, também descrito em Santos (1996). Esse movimento é responsável pelo contato interpessoal entre o remetente e o destinatário e é constituído por três passos: chamado, saudação e referências. O chamado (Cheung 1993) é constituído por uma frase de efeito que possui destaque tipográfico letras maiores, cores mais fortes etc. - e busca chamar a atenção do destinatário para o assunto tratado. Referências é uma alusão direta ao assunto tratado na carta, sintetizando o conteúdo do documento em uma proposição. Por último, a saudação é um cumprimento ao destinatário, cujo nome é antecido por partículas como caro, prezado.

O movimento seguinte, credenciais da empresa, tem por objetivo caracterizar a empresa remetente, enfatizando sua potencialidade, experiência, solidez e competência. A identificação de um movimento responsável por trazer informações sobre a empresa que comercializa os produtos/serviços anunciados também é encontrada no trabalho de Bhatia (1993a, b).

O movimento oferta é o mais longo e é dividido em quatro passos: Introdução da oferta; Detalhamento da oferta; Valor e Incentivos. Ele também é descrito na estrutura genérica de Bhatia (1993a, b); e o movimento Describing the product/service na estrutura de Cheung (1993). Introdução da oferta é responsável pela preparação do destinatário para a descrição da oferta propriamente dita. Nesse passo, o produto/serviço é apresentado, para, posteriormente, ser descrito em maiores detalhes. O detalhamento da oferta ocorre logo depois da introdução e traz dois tipos de informações sobre o produto e o serviço, explicando-o para o cliente. $O$ passo valor ocorre logo depois do detalhamento da oferta e traz informações sobre o preço para aquisição do produto/serviço. Já incentivos é o último passo desse movimento e traz vantagens oferecidas para aquisição do produto/serviço.

Demanda de ações é a parte da carta em que há uma tentativa de intervenção sobre o comportamento do destinatário, conforme descrito por Cheung (1993). Já o movimento documentos anexos pode ser encontrado na estrutura de Bhatia (1993a, b). Esse movimento traz informações sobre material anexo (folhetos, catálogos etc.) que complementam a descrição do produto/serviço. Por fim, o movimento finalização, também descrito por Santos (1996), é constituído pela identificação e/ou assinatura de um funcionário da empresa. 


\section{OS PROCESSOS NA ESTRUTURA GENÉRICA}

A figura 2 traz a distribuição dos processos pelas cartas. Os processos materiais são os mais freqüentes, seguidos pelos relacionais. Os verbais são o terceiro tipo mais freqüente, seguido pelos mentais e pelos comportamentais. Os processos existenciais são o tipo de processo com menor número de ocorrências.

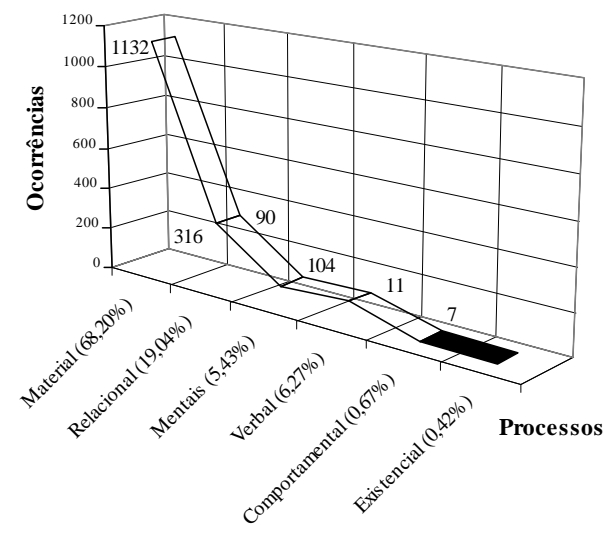

Figura 2: Processos e sua distribuição pelas cartas

Esses resultados corroboram outros estudos sobre transitividade, no que tange a sobre a frequiência dos processos. Entre esses trabalhos estão os de Matthiessen (1999) - que faz um levantamento quantitativo das estruturas de transitividade de vários tipos de textos -; Shimazumi (1996) - que estuda como a construção de papéis em contextos institucionais são refletidos no sistema da transitividade -; e Halliday (1992) - que analisa uma carta de mala direta para levantamento de fundos. Apesar de algumas variações na freqüência relativa dos processos, os materiais e os relacionais são os mais freqüentes nos corpora estudados por esses pesquisadores, sendo que os outros tipos de processo ocorrem sempre em números muito menores. Os corpora utilizados por Matthiessen (1999), Shimazumi (1996) e Halliday (1992b) são em língua inglesa, sendo que os dois úlimos não utilizam corpora abrangendo vários registros, e não apenas o publicitário. Isso pode levar a algumas diferenças em gêneros específicos, como é o caso de Martin (1991) e de Matthiessen (1999) que analisaram, entre outros gêneros, corpora compostos por material didático, mostrando que eles podem ter a predominância de processos relacionais, no caso do primeiro, ou de mentais, no caso do segundo. Isso parece mostrar que, apesar de haver a possibilidade de regularidade, gêneros específicos podem possuir distribuição própria, motivadade pelo seu contexto de 
LIMA-LOPES - Levantamento de processos materiais em cartas de mala direta.

ocorrência. De qualquer forma, esses resultados podem levar a duas hipóteses: 1) algumas características do sistema de transitividade podem ser comuns entre diferentes gêneros; $\mathrm{e}$ 2) a maior ocorrência desses dois tipos de processos pode ser uma característica de como o falante representa as experiências. No caso da hipótese 1), estudos comparativos poderiam mostrar se esse tipo de variação ocorre em diversos gêneros, de forma a observar se esse padrão se mantém. Já na hipótese 2), os estudos deveriam abranger várias línguas e gêneros, de forma a levantar as diferentes possibilidades de realização processual. Naturalmente, essas considerações devem ser ampliadas em outros estudos, uma vez que a comparação entre diferente gêneros não é o escopo desta pesquisa.

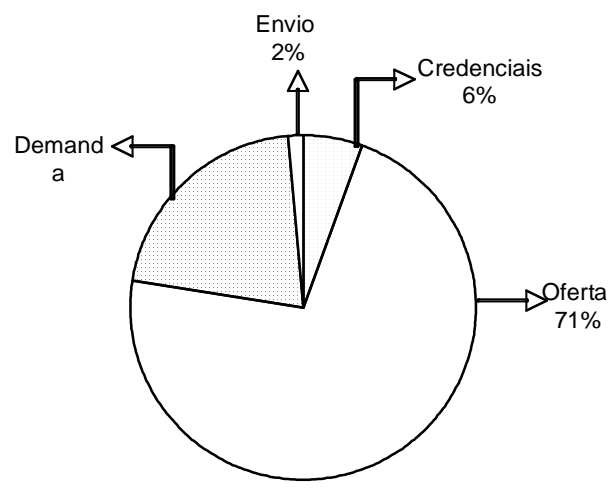

Figura 3: Concentração de processos nos movimento $\mathrm{N}=1666$

Um ponto importante a ser observado é que os processos não se distribuem igualmente pelos movimentos (figura 3). Oferta tem os maiores números, concentrando $71 \%$ de todos os processos, e, por conseguinte, veiculando grande parte das nos documentos. Na verdade, deve-se observar que o movimento oferta ocupa uma posição de destaque dentro desse gênero. Como já discutido (Lima-Lopes 2002, 2001), ele pode ser considerado o responsável pela descrição do produto/serviço e contém grande parte dos esforços e procedimentos argumentativos para a venda/contratação, o que também é verificado pelos estudos de Bhatia, (1993a,b) e Cheung (1993). Além disso, oferta é o único movimento que ocorre em todas as cartas. Isso parece mostrar que a importância de um movimento pode ser medida não apenas pela sua freqüência, como também pela quantidade de escolhas léxicogramaticais instanciadas. Os números de oferta são importantes por mostrarem que o 
movimento definidor do propósito comunicativo das cartas é também aquele que concentra a grande maioria das estruturas de transitividade. Conseqüentemente, poderíamos dizer que esse movimento também deve trazer a maior concentração de estruturas em outros sistemas, como o Temático ou ainda o Interpessoal.

Os processos nesse movimento podem realizar um grande número de funções, todos relacionados a diferentes significados veiculados nesse movimento. Observemos a figura 4 , a seguir.

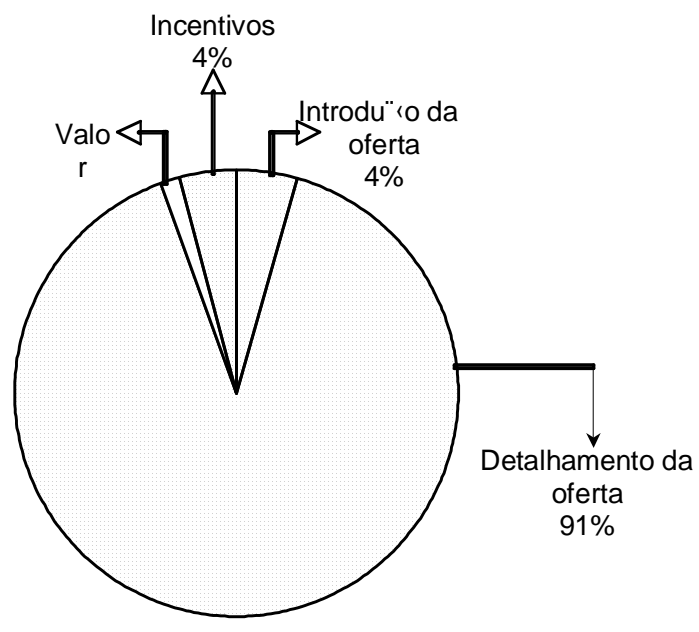

Figura 4: Os processos nos passos de oferta $\mathrm{N}=1184$

Podemos obsevar que o passo com maior número de processos é detalhamento da oferta, seguido por introdução da oferta, incentivos e valor. Aqui novamante há uma relação entre a quantidade de escolhas léxico-gramaticais e a freqüência de ocorrência, sendo que os passos mais importantes para a realização do movimento também concentram a maioria dos processos. Em outros trabalhos (Lima-Lopes 2002, 2001), observei que há diferença de importância entre os passos dentro de um movimento, o que chamei de hierarquia; o passo com maior importância seria o responsável por definir informação mais relevante em um movimento. O levantamento de processos parece confirmar a existência dessa hierarquia. No caso da oferta, o detalhamento da oferta é o passo mais importante, por 
LIMA-LOPES - Levantamento de processos materiais em cartas de mala direta.

ser não apenas o que está presente em todos os documentos, mas por concentrar a maioria das escolhas processuais. A introdução da oferta seria o passo seguinte, uma vez que ele é o segundo em freqüência e em concentração de processos. Já os demais passos (incentivos e valor) exercem funções de caráter secundário.

É importante observar que em oferta as funções realizadas pelos processos levam a diferentes padrões de realização dos participantes. No caso dos processos materiais em introdução da oferta, o participante que ocorre mais freqüentemente na posição de Ator é a empresa remetente, sendo que o produto/serviço anunciado realiza, nesses casos, a Meta ou a Extensão, ao passo que o destinatário das cartas é sempre o Beneficiário:

(1) AACME life e a ACME coleções [Participante: Ator] reuniram [Processo: Material] para você [Participante: Beneficiário] os mais famosos clássicos [Participante: Meta]. (Venda de coleções)

(2) A ACME [Participante: Ator] tem o prazer de apresentar[Processo: Material] [para você] [Participante: Beneficiário] o novo processador ACME III [Participante: Extensão].

Pode-se dizer que esse padrão de realização dos participantes é um resultado da funçãodesse passo, que é colocar o que é anunciado como resultado de ações realizadas pelaempresa remetente. Na ordem típica dos movimentos, a introdução da oferta antecede o detalhamento e ambos ocorrem depois de credenciais da empresa. Essa posição intermediária é uma possível explicação para os padrões e as representações levantados em introdução da oferta, pois esse passo parece servir como um elemento de transição entre as credenciais e o detalhamento, marcando a relação da empresa com o produto e da empresa/produto com o destinatário.

Nos processos relacionais, dois tipos de padrões são encontrados. No primeiro, explicase o que é anunciado pela sua inclusão em uma classe/conjunto formado por uma série de outros produtos/serviços da mesma espécie. Nesses processos, o que é anunciado exerce, sempre, a função de Portador. Por exemplo, ao classificar uma publicação como um suplemento, ela se torna diferente dos demais suplementos de um jornal, ao passo que classificar um serviço financeiro como crédito pessoal também é diferenciado dos outros tipos que possam existir:

(3) [O Jornal ACME] [Participante: Portador] Trata-se [Processo: relacional] de um Suplemento Especial que trará [Participante: Atributo]

(4) [O ACME PLUS] [Participante: Portador] Trata-se [Processo: relacional] do novo Crédito Automático ACME [Participante: Atributo]...

Esse tipo de significado também ocorre em detalhamento da oferta, no qual o mesmo padrão de fraseado é encontrado:

(5) [O suplemento][Participante: Portador] Será [Processo: relacional] um roteiro turístico [Participante: Atributo] ... 
De uma forma geral, a classificação do produto/serviço parece exigir um certo conhecimento do leitor, uma vez que, se ele não compartilhar a representação sugerida pelo escritor, ele pode não ser a pessoa para quem aquela carta é dirigida. Espera-se que o destinatário faça parte de uma comunidade que saiba o que aquele conceito significa.

Já em detalhamento da oferta, há uma variedade maior de processos e, conseqüentemente de padrões. Nos processos Materiais, três podem ser os padrões. No primeiro o Ator é realizado pelo que é anunciado, sendo que o beneficiário, quando presente, é o destinatário da carta:

6) As placas ACME [Participante: Ator] previnem [Processo: Material] contra $\operatorname{roub}((\mathrm{o}$ e ajudam no controle do seu patrimônio...

(7) Seu ACME clube [Participante: Ator] lhe [Participante: Beneficiário] dá [Processo: Material] acesso a feira [Participante: Meta].

Esse padrão de realização dos participantes pelas personagens coloca o produto/ serviço como benéfico para o seu consumidor possível e para o destinatário das cartas. Resultados semelhantes foram encontrados por Ramos (1997), que trabalha com projeção de papéis em materiais de promoção. A autora observou que os consumidores são representados como a entidade para quem algo é feito, e não como entidade-agente (Ramos, 1997: 197), o que acaba por retratar a empresa como entidade empreendedora e realizadora. Contudo, é importante ser observado que, no caso de detalhamento da oferta, o Ator é realizado por aquilo que é anunciado e não pela empresa, o que transfere essa representação para o produto/serviço. Isso se justifica pelo fato das cartas analisadas nesta pesquisa terem a promoção do produto/ serviço como passo central. Resultados semelhantes a este trabalho também foram encontrados por Martinez (1999).

No segundo padrão, o destinatário das cartas é o Ator:

(8) Você [Participante: Ator] vai pegar [Processo: Material] a direção e manobrar o seu negócio ...

(9) Você [Participante: Ator] pode cancelar [Processo: Material] sua assinatura a qualquer momento [Participante: Meta].

Nesses processos, dois significados são veiculados. No primeiro, o escritor parece representar o destinatário como usuário do produto/serviço, de forma a exemplificar o que é anunciado a partir daquele que faz (Ramos 1997: 158). Entretanto, eles são diferentes dos processos que possuem o produto/serviço como Ator, uma vez que o produto/serviço é descrito a partir de quem usa o que é anunciado e não a partir de sua capacidade de realização. Já no segundo, há significados de caráter procedural. Eles representam ações relacionadas à compra/contratação do que é anunciado, sendo que o destinatário não é obrigado a realizá-las.

Outro tipo de processo que merece destaque dentro de detalhamaneto da oferta são os relacionais. Além dos padrões já apontados acima (ver discussão do exemplo 
LIMA-LOPES - Levantamento de processos materiais em cartas de mala direta.

$\mathrm{X}$ ), observamos processos de identificação, que visam identificar um produto ou serviço como a melhor escolha naquele contexto:

(10) Sua melhor opção [Participante: Identificador] é [Processo: Relacional] $o$ ACME [Participante: Identificado]

(11) O novo processador ACME III de $466 \mathrm{MHz}$ Participante: Identificado] é Processo: Relacional] a mais recente aquisição [Participante: Identificador].

Essa particularização é uma forma de persuasão baseada na avaliação ${ }^{4}$ do que é anunciado, buscando-se fazer com que o destinatário também assuma essa representação do produto/serviço. Ramos (1996) coloca que a escolha dos participantes está condicionada pelos objetivos do texto. Assim, ao classificar o produto/serviço, o escritor não só está definindo o que é anunciado, como também está selecionando o seu leitor que, para entender essa definição, deve possuir conhecimentos específicos. Já nos processos de identificação, o produto/serviço é definido como o melhor, identificando-se com valores positivos que os destacam dos demais.

Entre os processos relacionais há os que indicam constituição, nos quais há a explicação das partes ou facilidades oferecidas pelo produto/serviço. Esse tipo de significado é sempre realizado pelos processos relacionais possessivos, sendo que há um padrão de realização dos personagens. Por exemplo, ao se explicar um software para contabilidade — que é o Possuidor - são destacadas algumas de suas funções — que são os Possuídos —, como mostra o exemplo a seguir.

(12) Os sistemas [Participante: Possuidor] possuem [Processo: Relacional] teclas de funções [Participante: Possuído].

Esse tipo de significado também pode ser instanciado em padrões em que o destinatário é o Possuidor, como vemos nos exemplos abaixo, retirados de cartas que vendem serviços bancários:

(13) Você [Participante: Possuidor] conta [Processo: Relacional] com 30 dias de transporte gratuito[Participante: Possuído].. .

(14) Você [Participante: Possuidor] conta [Processo: Relacional] com o valor acima que já está pré-aprovado [Participante: Possuído]

Passemos agora aos processos mentais, que nesse passo, exercem duas funções. Os processos de convite - sempre mentais de cognição — são usados em contextos em que o escritor convida o destinatário a conhecer e experimentar o que é anunciado:

\footnotetext{
${ }^{4}$ Thompson e Hunston (2000) definem avaliação como...the broad cover term for the expression of the speaker or writer's attitude or stance toward, viewpoint on, or feelings about the entities or propositions that he or she is talking about (Thompson e Hunston, 2000:05).
} 
(15) Se você [Participante: Experienciador] acredita que [Processo: Mental] estes povos indígenas têm algo a acrescentar à sua formação

Já nos processos de procedimento, o escritor mostra que o destinatário pode devolver o produto oferecido caso ele não atenda às suas expectativas. Esse tipo de processo sempre ocorre em orações condicionais, que são responsáveis pela idéia de devolução vinculada. Os processos mentais também realizam funções muito semelhantes aos materiais, uma vez que o destinatário é representado como usuário do que é anunciado. Por exemplo, o destinatário pode ser um usuário em caráter temporário, sendo o "experimentador" daquilo que é anunciado:

(16) Se você [Participante: Experienciador] não gostar [Processo: Mental], é só devolvê-lo [Participante: Fenômeno].

Esses processos trazem informações sobre o que o destinatário terá ao adquirir o serviço anunciado, representando o destinatário como usuário do serviço (podendo gozar, portanto, daquilo que ele oferece). Esses resultados também são similares aos levantados na análise dos processos materiais nesse passo. Uma possível explicação para isso pode ser a necessidade de se representar as personagens de forma similar em mais de um tipo de processo.

Os demais passos de oferta possuem pouca variação de funções e de processos. No caso de valor, os processos materiais são os mais importantes e possuem um padrão bem definido: quando o Ator é o destinatário, exemplo 17, ele é representado como comprador, ao passo que quando a empresa remetente é o Ator, como em 18.

(17) ...você [Participante: Ator] paga [Processo: Material] em até 15 vezes com uma das melhores taxas do mercado [Elemento circunstancial:Modo]

(18) Nós [Participante: Ator] debitaremos [Processo: Material] em seu cartão de crédito o valor inacreditável [Elemento circunstancial: Benefício] de $\mathrm{R} \$$ 9,90 [Participante: Meta].

Em incentivos há duas possibilidades de realização do papel de Ator: a empresa remetente e o destinatário. Quando a empresa remetente é Ator, ela é representada como oferecedor dos incentivos para compra do produto/serviço anunciado, enquanto que o destinatário é o receptor desses incentivos. Novamente o padrão de realização dos participantes é bem claro, sendo que a empresa representa o Ator e o Destinatário, o Beneficiário.

(19) Inicialmente a ACME [Participante: Ator] estará premiando[Processo: Material] seus clientes [Participante: Beneficiario].

Já nos processos em que o destinatário é o Ator o tipo de relação do destinatário com os incentivos é diferente, uma vez que essa personagem é retratada de forma mais ativa, 
LIMA-LOPES - Levantamento de processos materiais em cartas de mala direta.

conquistando o incentivo. Daí uma relação Ator/Beneficiário (Halliday, 1994), que se tece no ato da compra/contratação:

(20) E a partir do $2^{\circ}$ ano você [Participante: Ator] ainda ganha [Participante: Ator] $50 \%$ de desconto em todas as anuidades [Participante: Meta]

Já demanda de ações se caracteriza por ser o o segundo movimento com maior número de processos além de ser, como já vimos anteriormente, o segundo a ser realizado mais frequientemente nas cartas. Nesse ponto, é oportuno retomar alguns conceitos sugeridos por Thompson e Thetela (1995), para quem um anúncio de produtos/serviços pode ser visto, essencialmente, como um comando. Em seu trabalho, os autores discutem quais são as principais formas de realização de comandos em materiais publicitários, apontando que eles têm seu impacto diminuído através de um sistema que envolve diversas estratégias. Assim, a utilização de comandos na forma de demandas, pedidos ou sugestões é um ponto importante na definição de qualquer documento publicitário.

Os principais tipos de processos nesse movimento são os Materiais e os Verbais. No caso dos processos Materiais, o que encontramos são proposições que parecem levar os destinatários à compra ou contratação do que é anunciado. Nesse contexto, o produto e serviço ocorre como Meta ou extensão, na realização das demandas ostensivas:

(21) [você] [Participante: Ator] Faça [Processo: Material] o seu seguro ACME [Participante: Meta].

(22) [você] [Participante: Ator] Começe [Processo: Material] já o programa de patrimônio de sua empresa [Participante: Meta].

Em demandas, podemos encontrar processos que não visam a aquisição, mas sim procedimentos relacionados a etapas ou ações que devem ser cumpridas para que haja a formalização da compra/contratação do produto/serviço oferecido. Aqui o Ator é o destinatário das cartas:

(23) [você] [Participante: Ator] Preencha e envie [Processos: Material] a proposta anexa [Participante: Meta] pelo correio (não é necessário selar)...

Essa função é muito similar à realizada pelos processos verbais. A única diferença é o tipo de procedimento que se parece exigir, uma vez que, nesses processos, há o estabelecimento de um contato verbal entre a empresa e o destinatário. Busca-se um processo de negociação que, eventualmente, levará à aquisição do produto/serviço, sendo que o Receptor é instanciado pela empresa remetente:

\footnotetext{
${ }^{5}$ Consultar é um verbo que possui mais de uma possibilidade de classificação: uma comportamental e outra verbal, que se aplica a este estudo, onde ele é sinônimo de perguntar ou informar-se, como mostram os exemplos: (i) Pergunte em sua agência. . . e (ii) Informe-se em sua agência. . .
} 
(24) Para maiores informações, \{você $\}$ [Participante: Dizente] fale [Processos:Verbal] conosco [Participante: Receptor].

(25) Havendo interesse de trocar ou vender vosso equipamento, \{você\} [Participante: Dizente] consulte ${ }^{5}$ Processos:Verbal]-nos [Participante: Receptor].

Os movimentos credenciais da empresa e documentos anexos estão entre os movimentos com menor número de processos, além de serem, também, os que ocorrem em menor frequiência nas cartas. Com relação ao primeiro, pode-se justificar as baixas frequiências graças ao propósito comunicativo das cartas, que é vender produtos/serviços, fazendo com que o foco principal dos documentos esteja no que é anunciado e não na empresa. As cartas de venda são documentos utilizados na promoção de produtos e serviços, caracterizando-se por serem documentos publicitários (Cesca, 1995; Pinho, 1990); uma implicação disso é a necessidade do escritor direcionar seus esforços para convencer os destinatários das cartas a adquirir o produto/serviço anunciado. Como já demonstrei em outro estudo (Lima-Lopes 2002, 2001) utilizando o mesmo corpus, esses esforços estão concentrados, principalmente, em 2 movimentos. Em Oferta, o produto e o serviço são detalhados a partir de vários aspectos, ao passo que, em demanda de ações, o escritor tenta intervir diretamente no comportamento do destinatário. Esses resultados fazem desses movimentos os mais importantes dentre todos os demais: uma vez que eles são não apenas os mais freqüêntes, como também os que concentram maior número de intanciações. $O u$ seja, sua grande relevância dentro da estrutura retórica é refletida não só na sua freqüência de ocorrência, como também na quantidade das escolhas léxico-gramaticais.

Nesse movimento, os processos tem uma função caracterizadora, uma vez que todos são utilizados de forma a definir a empresa. No caso dos processos materiais, apenas a empresa remetente ocorre como Ator, o que pode ser explicado pela função desse movimento: definir a empresa como entidade de qualidade, capaz e confiável:

(26) [Nós] [Participante: Ator] Também realizamos [Processo: Material] pesquisas qualitativas esporádicas e pesquisas...

(27) A editora ACME [Participante: Ator] sistematicamente tem investido [Processo: Material] em pesquisas...

Esses resultados também corroboram outros estudos em GSF, como é o caso de Ramos (1997), Thompson e Thetela (1995) e Martinez (1999). No trabalho de Ramos (1997:197), a empresa remetente é retratada como entidade empreendedora e realizadora, que beneficia os destinatários e clientes, ao passo que os estudos de Thompson e Thetela (1995) e Martinez (1999) também identificam a empresa como potencialmente benéfica para o destinatário. Isso nos permite afirmar, mesmo que especulativamente, que essa representação da empresa é algo comum à realização de processos materiais em vários tipos de textos promocionais, podendo ser uma característica desse tipo de discurso. Por outro lado, o tipo de representação veiculada pelos processos de experiência não foi encontrada em nenhum dos estudos acima, o que talvez indique que essa representação é uma característica do gênero analisado nesta pesquisa. 
LIMA-LOPES - Levantamento de processos materiais em cartas de mala direta.

No caso dos processos relacionais, encontramos os mesmos padrões funcionais de detalhamento da oferta e introdução da oferta. Aqui, observamos que a empresa é associada a valores que a destacam em relação às outras empresas de sua área, retratando o seu grau de excelência (exemplo 28), ou ainda é caracterizada como parte de um grupo ou classe que engloba outras companhias que atuam na mesma área (exemplo 29).

(28) A ACME [Participante: Identificado] informática se propõe [Processo: Relacional] em primeiro lugar em ser a melhor sem ser a maior [Participante: Identificador]

(29) [Nós] [Participante: Portador] Somos [Processo: Relacional] especializados na área contábil [Participante: Atributo] e por esse motivo atualizamos os sistemas com maior facilidade.

Já no caso de documentos anexos pude observar que, em várias cartas, a presença de folhetos ou catálogos não é comunicada ao destinatário, embora eles as acompanhem. Talvez isso aconteça devido à economia de espaço: a presença da documentação é auto-observável, o que dispensaria a utilização de recursos lingüísticos em sua realização, justificando sua baixa freqüência nas caixas, assim como o baixo número de processos.

Nesse movimento, temos apenas a instanciação de processos materiais. O destinatário é Ator em apenas um processo: receber. Ali ele é Ator com traços de Beneficiário (Halliday, 1994), o que ocorre devido à natureza da ação realizada, uma vez que o ato de recebimento desses documentos pressupõe seu envio pelo remetente:

(30) Você [Participante: Ator] está recebendo [Processo: Material] o guia ACME [Participante: Meta]...

(31) ... você [Participante: Ator] está recebendo o programa do seminário[Participante: Meta]...

Já nos processos nos quais o Ator é a empresa remetente, o destinatário é o Beneficiário das ações de envio, podendo estar ou não estar expresso na proposição. No primeiro caso, exemplo (160), o Beneficiário não é instanciado; ele parece ser recuperável pelo contexto, uma vez que o destinatário é quem está recebendo a carta e, logicamente, os documentos. Já no segundo, há sempre a utilização do pronome the.

(32) \{Nós\} [Participante: Ator] Estamos encaminhando [Processo: Material] (anexo) \{para você leitor\} [Participante: Beneficiário] um briefing do jornal ACME[Participante: Meta] ...

(33) ... \{Nós\}[Participante: Ator] estamos lhes [Participante: Beneficiário] enviando o catálogo anexo [Participante: Meta]...

\section{OS PROCESSOS E AS VARIAÇÕES NO CAMPO}

Um ponto a ser observado é que nem todos os processos comportam-se da mesma forma em relação ao campo do discurso. De fato, dois tipos de variação podem ocorrer: 1) variação 
Trabalhos em Lingüística Aplicada 44(1) - Jan./Jun. 2005

em relação ao tipo de carta e movimento, aqui os processos que ocorrem apenas em documentos que vendem apenas um produto ou serviço e apenas em um movimento; e 2) variação apenas em relação ao movimento, na qual alguns tipos de processos podem ser exclusivos de um movimento mas ocorrer em cartas que vendem vários produtos ou serviços.

Oferta é o movimento que mais sofre o primeiro tipo de variação. Essa variação ocorre porque um de seus passos, detalhamento da oferta, tem por objetivo descrever o produto/serviço através da caracterização pelo seu desempenho é algo refletido nas escolhas dos processos, que estão relacionados, em diferentes graus, às especificidades de cada produto/serviço. Assim, circular ocorre apenas em cartas que vendem publicações (exemplo 34), ao passo que integrar (exemplo 35) somente nas de hardware para computadores.

(34) ACME ACME circulará [Processo: Material] toda a última quinta-feira

(35) O novo chipset ACME integra [Processo: Material] a solução 3D graphics...

Da mesma forma, cancelar ocorre apenas em cartas que vendem assinaturas de coleções de vídeo e cds, ao passo que circular apenas nas de publicações.

(36) Você pode cancelar [Processo: Material] sua assinatua a qualquer momento...

(37) O suplemento ACME circulará [Processo: Material] toda última quinta-feira de cada mês.

Em oferta esse tipo de varição também é encontrada em introdução da oferta, onde diferentes produtos podem ser introduzidos por processos também diferentes:

(38) A ACME phone criou uma promoção especial: ao viajar para o exterior você faz as sua ligações...

(39) A ACME life e a ACME coleções reuniram [Processo: Material] para você os mais famosos clássicos...

(40) ... a nova programação da ACME TV estréia [Processo: Material] em abril...

No caso de valor essa variação pode ser representada pelos verbos pagar e debitar (exemplos a seguir), que têm como Meta/Extensão o valor a ser pago:

(41) 5x de 38,00 que você paga [Processo: Material] com seu cartão de crédito ou débito em conta corrente. .

(42) Nós debitaremos em seu cartão de crédito o valor inacreditável de R \$9,90.

Outro exemplo dessa variação nos processos é Demanda de ações, cuja função é levar o destinatário a compra ou ao contato com a empresa. Aqui as variações de campo parecem estar ligadas ao tipo de função realizada: quando há uma ordem de compra, a tendência dos processos é ocorrer em apenas um tipo de cartas, como é o caso de (43), retirado de uma carta que vende espaços publicitários, e (44), que vende um serviço de pager. 
LIMA-LOPES - Levantamento de processos materiais em cartas de mala direta.

(43) Não deixe de anunciar [Processo: Material/Verbal] nesta edição de ACME...

(44) Reative [Processo: Comportamental] seu pager agora mesmo e GANHE ...

É importante observar que essa variação concentra-se, principalmente, em oferta e demanda de ações. Por exemplo, em detalhamento da oferta, processos como prevenir (45), que ocorre em cartas que vendem placas de proteção patrimonial e ampliar, presente somente nas cartas que vendem serviços de telecomunicação (46), cumprem a função de explicar o produto/serviço em termos daquilo que ele pode realizar.

(45) As placas ACME previnem [Processo: Material] contra roubo e ajudam no controle do seu patrimônio...

(46) É um superpacote de serviços suplementares que amplia [Processo: Material] as vantagens do seu celular.

No caso de demanda de ações, essa variação ocorre porque os processos trazem demandas que são baseadas nas especificidades daquilo que se anuncia. Por exemplo, receber (47) ocorre apenas em cartas que vendem coleções, ao passo que certificar-se (48) está presente somente nas que anunciam placas de proteção partimonial. O mesmo se aplica a processos como anunciar (exemplo 43, acima) e reativar (exemplo 44, acima), além de programar, presente apenas na carta que vende anúncios televisivos (49), e começar (50), presente apenas em uma carta que vende placas patrimoniais.

(47) ...receba [Processo: Material] o álbum de 2 CDs da coleção ACME COMPOSITORES...

(48) Certifique [Processo: Material] -se que o patrimônio Empresa Cortejada esteja protegida.

(49) Programe [Processo: Material] a rede ACME!

(50) Começe [Processo: Material] já o programa de patrimônio de sua empresa...

Em outras palavras, nos dados não há ocorrência de ações como receber um anúncio de jornal, ou assinar a ativação de um pager, começar uma rede de TV, ou mesmo certificarse de uma coleção. Isso acontece porque há uma relação de colocação entre o processo e a Meta/Extensão que é realizada pelo produto/serviço anunciado, fazendo com que o sentido seja construído pela ocorrência conjunta desses elementos.

Já o segunto no tipo de variação, a instancialção está ligada apenas ao movimento/ passo em que um dado processo ocorre. Um exemplo dessa variação é oferecer, em detalhamento da oferta e apresentar em introdução da oferta:

(51) O Real Seguro Universitário oferece [Processo: Material] a você, neste caso, o pagamento de indenização de até $\mathrm{R} \$ 1.20$

(52) Ele lhe dará [Processo: Material] maiores detalhes sobre tudo o que o seu SuperCartão Santander tem a lhe oferecer. 
(53) ....apresentamo [Processo: Material] -lhes nossos serviços, trazendo produtos e assistência técnica...

(54) A ACME tem o prazer de apresentar [Processo: Material] [para você] o novo processador ACME III.

É importante observar que, nessa variação, os processos podem ocorrer em cartas que vendem mais de um tipo de produto/ serviço, mas nunca em mais de um movimento. Um exemplo desse tipo de processo é aceitar, que ocorre na venda de coleções (56), e na de serviços financeiros (55), bem como preparar, que ocorre em cartas que vendem seguros (57), e serviços de investimento bancário (58):

(55) Aceite [Processo: Material] este convite e aproveite uma oferta ...

(56) Aceite [Processo: Material] nosso convite e entre para este seleto grupo...

(57) Nós preparamos [Processo: Material] para você, estudante, uma oferta especial...

(58) Por isso, nós preparamos [Processo: Material] uma oferta exclusiva: Abrindo sua...

Ainda nesse movimento, outro exemplo é incentivos, passo em que dar é um dos poucos processos instanciados, sendo uma escolha presente em vários tipos de produto/ serviço:

(59) Seu ACME lhe dá [Processo: Material] acesso gratuito ao evento e ainda lhe possibilita... (venda de cartões de crédito)

(60) Por isso, damos [Processo: Material] a você a oportunidade de assistir ao 10. vídeo por uma semana ... (venda de coleções de vídeo)

Se por um lado essas escolhas parecem ser de caráter mais geral, adaptáveis a mais de um contexto e menos sensíveis a um certo tipo variações no campo, uma vez que elas não levam em conta as especificidades do que é anunciado, por outro lado elas são instanciadas apenas em um movimento. Isso parece mostrar que há diferentes tipos de variação de campo, as quais podem estar ligadas tanto ao assunto tratado, que aqui tem o produto/ serviço como foco central, como a função realizada por um movimento ou passo. É importante observar que essas variações podem ocorrer simultaneamente. Ou seja, um processo pode ocorrer nas cartas que vendem apenas um tipo de produto ou serviço, além de ser instanciado em apenas um movimento ou passo.

Dois movimentos chamam a atenção devido sua falta de variação. São eles: credenciais da empresa e documentos anexos. No caso do primeiro, apesar de não haver processos que se repetem em mais de uma carta (exemplos a seguir), não podemos afirmar que isso seja uma variação. Isso porque a quantidade de instanciações é muito pequena (ver figura 1), justificando a ausência de repetição.

(61) A ACME conquistou [Processo: Material] o certificado de qualidade iso9002...

(62) Estamos desenvolvendo [Processo: Material] nossa equipe de vendas... 
LIMA-LOPES - Levantamento de processos materiais em cartas de mala direta.

Já em documentos anexos, os processos se repetem em várias cartas (exemplos a seguir). Esse movimento tem a função de avisar o leitor da existência de documentos. Nesse movimento, ainda temos a possibilidade de uma não realização lingúística, dado que a presença desses documentos pode ser percebida pelo leitor da carta.

(63) você está recebendo [Processo: Material] o programa de seminários...

(64) estamos thes enviando [Processo: Material] o catálogo anexo, que apresenta o conjunto de cursos oferecidos nas área...

Como já colocado na fundamentação teórica, a análise dos movimentos e passos (Lima-Lopes, 2001; 2002) mostrou que eles, além de ocorrem em um baixo número de cartas, também têm números modestos na concentração de processos, sendo, portanto, secundários na realização do propósito comunicativo das cartas, o que é relfetido nas variações do campo.

\section{CONSIDERAÇÕES FINAIS}

O levantamento dos processos foi um instrumento eficaz, mostrando que questões relacionadas à transitividade são importantes para o estudo de gêneros. Um dos resultados mais relevantes foi o levantamento de funções presentes em cada movimento. Pude observar que a quantidade de processos em cada movimento (ou passo) possui alguma relação com sua frequiência no corpus estudado: aqueles que ocorrem mais vezes, tendem a possuir mais processos, os quais realizam mais funções. Por exemplo, credenciais da empresa descreve a empresa remetente, destacando sua potencialidade e capacidade, utilizando processos materiais, bem como classificando e avaliando-a, utilizando processos relacionais.

Oferta é o movimento com maior complexibilidade e diversidade de funções, o que acontece devido ao número de passos que o compõem, cada um com um papel específico. Por exemplo, a introdução da oferta tem o objetivo de apresentar o que é anunciado para o destinatário, o que pode ocorrer pela disponibilização do produto ou pela criação do que é anunciado. Em detalhamento da oferta, há a descrição do produto/serviço através de: a) ações realizadas pelo produto - mostrando aquilo que o produto pode realizar -; b) uso do produto/serviço - mostrando o que o destinatário pode fazer com o produto - e c) sua classificação e avaliação - categorizando e destacando o que é anunciado. Já em valor, o preço do produto/serviço pode ser exposto de duas formas: a) ações de cobrança realizadas pela empresa — e b) ações de pagamento — realizadas pelo destinatário. Por fim, em incentivos, os descontos e outras facilidades podem ser obtidos pelo destinatário ou cedidos pela empresa.

Demanda de ações é o segundo movimento com maior número de processos e com maior ocorrência nas cartas. Suas funções principais são levar o destinatário a comprar o produto ou a estabelecer algum tipo de contato com a empresa. Já os demais movimentos, 
além de ocorrerem em baixa freqüência, possuem poucos processos, realizando funções menos relevantes.

Isso faz com que cada movimento (ou passo) tenha um grande número de funções exclusivas, as quais parecem estar veiculadas ao objetivo específico de cada um deles. São essas diferenças que permitem distinguir os movimentos e passos da carta: cada uma delas é responsável por parte do processo argumentativo, concentrando significados que definem sua função na estrutura retórica dos documentos.

Parte dessas funções é realizada por mais de um tipo de processo. Por exemplo, em oferta, cada um de seus passos possui um padrão próprio; no caso de introdução da oferta, a disponibilização dos produtos ocorre com os processos materiais e relacionais. Em descrição da oferta, significados procedurais estão presentes em processos materiais, verbais e mentais; significados relacionados à descrição do produto - o que ele faz e o que pode ser feito com ele - são veiculados pelos processos materiais, relacionais possessivos e comportamentais, ao passo que a expressão do conteúdo do produto/serviço ocorre nos processos verbais e materiais. Já a conquista de incentivos ocorre nos processos relacionais e materiais. Por fim, em demanda de ações, as demandas de compra e contato ocorrem tanto nos processos materiais como nos processos verbais. Assim, os processos podem ter seu significado determinado (ou mesmo condicionado) pelas funções realizadas em cada um dos movimentos, mostrando que eles diferem não apenas na quantidade das escolhas.

A observação dessas funções nos permite três generalizações:

1) Cada movimento (e passo) tem um conjunto próprio de funções: essa característica é um dos elementos responsáveis pela diferenciação entre as diversas partes de um texto,uma vez que essas funções estão presentes apenas em um movimento/passo.

2) As funções são realizadas por diversos tipos de processos: os significados trazidos por um movimento ou passo são realizados por mais de um tipo de processo, mostrando que são esses significados que condicionam as escolhas processuais.

3) A similaridade de função entre processos difere de movimento para movimento: nem todos os processos ocorrem em todas as funções, mostrando que a similaridade entre os processos é resultado do tipo de significado veiculado por cada parte do texto.

Um fato importante é que esses significados possuem padrões de escolha que parecem espelhar uma representação de mundo, as quais são expelhados nos padrões de realização dos participantes, como podemos observar no quarto abaixo: 
LIMA-LOPES - Levantamento de processos materiais em cartas de mala direta.

\begin{tabular}{|c|c|c|c|}
\hline $\begin{array}{l}\text { Participante da } \\
\text { interação }\end{array}$ & Representação & Padrão de realização & $\begin{array}{c}\text { Movimentos } \\
\text { (Passos) }\end{array}$ \\
\hline Destinatário & Comprador/ Usuário & $\begin{array}{c}\text { Ator/Comportante/ } \\
\text { Dizente/Experienciador }\end{array}$ & $\begin{array}{c}\text { Detalhamento da } \\
\text { oferta } \\
\text { Demanda de ações }\end{array}$ \\
\hline Destinatário & Beneficiado & Beneficiário & $\begin{array}{l}\text { Detalhamento da } \\
\text { oferta } \\
\text { Introdução da oferta } \\
\text { Incentivos } \\
\text { Documentos anexos } \\
\text { Credenciais da } \\
\text { empresa } \\
\text { Detalhamento da } \\
\text { oferta } \\
\text { Introdução da oferta } \\
\text { Incentivos } \\
\text { Documentos anexos }\end{array}$ \\
\hline Produto & $\begin{array}{c}\text { Elemento } \\
\text { Comprado/usado }\end{array}$ & Meta/Extensão Possuído/Fenômeno & $\begin{array}{c}\text { Detalhamento da } \\
\text { oferta } \\
\text { Demanda de ações }\end{array}$ \\
\hline Produto & $\begin{array}{c}\text { Elemento } \\
\text { Feito/disponibilizado }\end{array}$ & $\begin{array}{c}\text { Possuído/ } \\
\text { Meta/Extensão }\end{array}$ & $\begin{array}{c}\text { Introdução } \\
\text { da oferta }\end{array}$ \\
\hline
\end{tabular}

Quadro 01: Padrões e representações nas cartas

Talvez a representação mais importante da empresa e do produto/serviço seja a de benfeitor em relação ao destinatário ou cliente, o que corrobora os resultados de Martinez (1999), Ramos (1997) e Thompson e Thetela (1995). Aqui, a empresa e o produto/serviço são colocados como benéficos para o possível comprador, sendo que essa relação é refletida na escolha do destinatário/cliente como beneficiário em credenciais da empresa, introdução da oferta, detalhamento da oferta e incentivos. No caso de credenciais da empresa, o cliente se beneficia dos investimentos da empresa e da qualidade dos seus produtos/serviços; em introdução da oferta, o destinatário é para quem a oferta é dirigida; ao passo que em detalhamento da oferta, o destinatário se beneficia da performance do produto/serviço; e em incentivos, dos descontos e vantagens dadas. Dois movimentos, incentivos e envio de documentos, possuem questões interessantes a serem colocadas. Em incentivos, o destinatário pode também ser agente em processos materiais e possuidor em relacionais: nesses contextos, ele parece guardar traços de beneficiário, uma vez que sua ação de recebimento está condicionada à compra do produto/serviço. Já em envio de documentos, a empresa remetente é ator em processos onde o beneficiário não está presente na oração, mas pode ser recuperado pelo contexto, uma vez que é para o destinatário que esses documentos estão sendo enviados.

Esses padrões mostram que a empresa remetente está preocupada em representar a si e seus produtos/serviços como benéficos para seu público-alvo, no qual o destinatário está 
incluso. Esse tipo de relação também está presente nas estratégias de aproximação em credenciais da empresa - no qual a empresa é colocada como conhecedora da realidade do destinatário - e em detalhamento da oferta — onde o produto é colocado como responsável pela modificação do dia-a-dia do destinatário. Em outra representação importante, o destinatário é o comprador/usuário do produto/serviço. A estratégia aplicada é fazer com que o destinatário se identifique com o produto/serviço anunciado, sendo que o destinatário é agente em processos nos quais o produto/serviço é a entidade afetada pela ação. Por exemplo, em detalhamento da oferta, o destinatário ocorre como Ator/Possuidor/ Comportante em processos onde o produto/serviço é Meta/Extensão/Possuído, ao passo que, em demanda de ações, o destinatário é o Ator/Dizente em processos que de que os movimentos que constituem a estrutura retórica de um gênero podem possuir diferenças.

Este trabalho estuda as variações dos processos de acordo com o campo do discurso. Os resultados mostram que há diferenças nas escolhas dos processos em cartas que vendem diferentes tipos de produtos/serviços, o que não atinge todos os tipos de processos e movimentos de forma igual. As variações no campo estão concentradas principalmente na oferta e na demanda de ações, dentro dos processos materiais. Os momentos onde essa variação é mais expressiva são os movimentos mais importantes do gênero, mostrando que há uma relação entre a quantidade de escolhas léxico gramaticais e a importância de um movimento (ou passo) para a estrutura retórica de um gênero, concentrando-se, nos processos materiais, que são os mais freqüentes. Isso pode significar que há uma relação entre a quantidade de escolhas dentro do sistema de transitividade e a variação no campo em cada tipo de processo: os mais usados devem ser aqueles onde a variação é maior.

É importante perceber que essas variações de campo ocorrem, principalmente, nos movimentos que também são responsáveis pela descrição do produto / serviço. De fato, isso deve ocorrer porque a descrição do que se vende, a partir dos resultados obtidos nesta pesquisa, pode ser encarado como o coração das cartas. Não obstante, deve-se observar que a descrição desse produto / serviço, apesar de seguir algumas regras pré-estabelecidas, terá escolhas que serão vinculadas às especificidades daquilo que é vendido: um computador é diferente de uma câmara de vídeo, sendo ambos diferentes de um jornal. São essas diferenças que particularizam os documentos em relação às escolhas processuais realizadas. Assim, apesar do discurso dessas cartas ser organizado a partir de padrões organizacionais e lingüísticos bem claros e estruturados, alguma variação é pertinente àquilo que se vende sem, contudo, haver uma quebra do gênero. Em outras palavras, no corpus estudado, parecem existir macro-escolhas (papéis assumidos e projetados) comuns ao gênero, os quais são instanciados por processos que variam de acordo com o assunto tratado (aquilo que se vende).

Outra contribuição é mostrar que a observação das escolhas no sistema de transitividade pode ser útil na análise do gênero. $\mathrm{O}$ modelo de análise utilizado nesta pesquisa pode servir como base não apenas para estudos de cartas comerciais como também de outros textos. Os estudos sobre gênero em geral privilegiam o levantamento de estruturas genéricas, de elementos lexicais que marcam a transição entre os diferentes movimentos e que evidenciam o conteúdo ideacional e interpessoal, ou, então, trabalham com a questão da 
LIMA-LOPES - Levantamento de processos materiais em cartas de mala direta.

formação da imagem e discurso. Há poucos trabalhos que utilizam o sistema de transitividade como base para a investigação dos movimentos e das representações em um gênero. No caso deste trabalho, a transitividade serviu como critério de diferenciação entre os movimentos e passos, validando a divisão que realizei.

O levantamento dos processos e seus participantes foi um instrumento eficaz para a análise do gênero, mostrando que questões relacionadas à transitividade são relevantes para análise, e evidenciando que os movimentos que constituem a estrutura retórica de um gênero podem possuir diferenças em vários níveis, entre elas:

1. a natureza dos processos: cada movimento possui um conjunto próprio de processos;

2. a quantidade de processos: os movimentos mais importantes para a estrutura retórica posssuem maior quantidade de processos;

3. o grau de variação no campo do discurso: o tipo de função realizada por um movimento (ou passo) determina o grau de variação no campo;

4. a função de cada movimento e passo: as funções de cada movimento (ou passo) são um elemento importante na escolha dos processos;

5. e a realização dos participantes: há uma relação sistemática ente a realização dos processos, seus agentes e as representações de mundo descrito pelas cartas.

Esses resultados são significativos por apontarem um novo caminho para os estudos de gêneros e de segmentação textual: devemos não apenas procurar elementos que marcam as fronteiras entre movimentos (ou passos), mas devemos também trabalhar com as escolhas que caracterizam cada um deles, de forma a melhor entender porque eles possuem diferentes funções.

Um ponto relevante é que o estudo aqui desenvolvido não traz contribuições apenas teóricas: ele pode também ser aplicado à produção de materiais para o ensino de línguas. Uma vez que foi possível observar quais foram as funções e representações veiculadas pelas escolhas dentro de cada movimento, sugere-se que o ensino de gêneros pode partir também desses resultados. Esse tipo de abordagem pode ajudar a construir um interlocutor mais competente, uma vez que ele poderá conhecer não apenas quais movimentos estão presentes em um gênero, mas também como os significados são veiculados em cada um deles, e quais são os seus padrões mais comuns. Ao mesmo tempo em que são ensinadas categorias abstratas, é necessário mostrar que há uma série de caminhos e escolhas possíveis que as concretizam, mostrando a relação entre as escolhas e o contexto onde um texto se insere (Martin, 2000). A aplicação desses resultados, por exemplo, resultou em bons frutos em meu trabalho como professor de língua portuguesa e redação em cursos de publicidade e propaganda, pois pude utilizar a abordagem genérica e os estudos de elementos léxicos gramaticais como ferramentas para mostrar aos alunos quais as especificidades das cartas, facilitando a comunicação com o público-alvo do trabalho. 


\section{REFERÊNCIAS BIBLIOGRÁFICAS}

ASTON, G. (1995). Corpora in language pedagogy: matching theory and practice. In G. COOK e B. SEIDLHOFER (eds.) Principle and practice in Applied Linguistics - studies in honour of H. G. Widdowson. Oxford: Oxford University Press.

BAPTISTA, M. E. (1998). E-mails na troca de informação numa multinacional:O gênero e as escolhas léxicogramaticais. Dissertação de Mestrado, LAEL - PUCSP.

BERBER SARDINHA, A. P. (1999). Lingüística do corpus e ensino-aprendizagem de línguas. Mímeo.

BHATIA, V. K. (1993a). Analysing genre: language use in professional settings. London: Longmam. . (1993b). Description to explanation in English for professional communication: application of genre analysis. In T. BOSWOOD; R. HOFFMAN e P. TUNG (eds.) Perspectives of English for professional communication. Hong Kong: City Polytecnic of Hong Kong.

BIBER, D.; CONRAD, S. e REPPEN, R. (1999). Corpus Linguistics: investigating language strutucture and use. Cambridge: Cambridge University Press.

BRESSANE, T. B. R. (2000). Construção de identidade numa empresa em transformação.Dissertação de Mestrado, LAEL - PUCSP.

CHEUNG, B. M. K. (1993). Text analysis of direct mail sales letters. In BOSWOOD, T; HOFFMAN, R. e TUNG, P. (eds.) Perspectives on English for professional communication. Hong Kong: City of Polytechnic of Hong Kong.

EGGINS, S. (1994). An introduction to systemic functional grammar. London: Printer Publishers.

EGGINS, S. e MARTIN, J. R. (1997). Genres and registers of discourse. In T. A. VAN DIJK (ed.) Discourse as structure and process. Amsterdan SAGE Publications.

GHADESSY, M. (1993). On the nature of writen business communication. In: GHADESSY, M. (ed.) Register analysis - theory and practice. London: Printer Publishers.

HALLIDAY, M. A. K. (1973). Explorations in the Functions of Language. London: Edward Arnold. (1976). Estrutura e função da linguagem. In J. LYONS (ed.) Novos Horizontes em Lingüística. São

Paulo: Cultrix/EDUSP. . (1978). Language as social semiotic. London: Edward Arnold. . (1985). An introduction to Functional Grammar. 1 ed. London: Arnold.

. (1991). Corpus studies and probabilistic grammar. In K. AIJMER e B. ALTERNBERG (eds.) i London: Longman.

. (1992a). Language as system and language as instance: the corpus as a theoretical construct. In: SVARTIVIK, J. (ed.) Directions on Corpus Linguistics: Proceedings of the Nobel Symposium 82. Stockholm: Mouton de Gruyer.

. (1992b). Some lexicogrammatical features of the zero population growth text. In: MANN, W. C. e THOMPSON, S. A. (eds.) Discourse Description: Diverse linguistic analyses of a fund-raising text. Amsterdan: John Benjamim.

(1993). Quantitative studies and probabilities in grammar. In M. HOEY (ed.) Data,description, discourse. London: Harper Collins.

. (1994). An introduction to Functional Grammar. 2 ed. London: Arnold.

HALLIDAY, M. A. K. e HASAN, R. (1989). Language, context and text: aspects of language in a socialsemiotic perspective. Oxford: Oxford University Press. 
LIMA-LOPES - Levantamento de processos materiais em cartas de mala direta.

HEBERLE, V. M. (1999). A representação das experiências femininas em editoriais de revistas para mulheres. Discurso y Sociedad, 1(3).

KENNEDY, G. (1998). An introduction to corpus linguistics. London: Longman.

LIMA-LOPES, R. E. (2001). Estudos de Transitividade em Língua Portuguesa: O Perfil do Gênero Cartas de Venda. Dissertação de Mestrado, LAEL-PUCSP. . (2003). A estrutura genérica em cartas de venda. Mímeo.

MARTIN, J. R. (1991). Nominalisation in science and humanities: distilling knowledge and scaffolding text. In VENTOLA, E. (ed.) Functional and Systemic Linguistics: Approaches and Uses. Mouton de Gruyter.

MARTIN, J. R.;MATTHIESSEN, C. M. I. M. e PAINTER, C. (1997). Working with functional grammar. London: Edward Arnold.

MARTINEZ, M. S. (1999). Mood choice and their associated functions in promotional texts. Mimeo.

MATTHIESSEN, C. M. I. M. (1999). The system of TRANSITIVITY: An exploratory tex-based profile. Functions of Language, 6 (1), p.1-51.

MCENERY, T.; WILSON, A. (1996). Corpus Linguistics. Edinburgh: Edinburgh University Press.

RAMOS, R. C. G. (1997). Projeção de imagens através de escolhas lingüisticas: um estudo no contexto empresarial. Tese de Doutoramento, LAEL - PUCSP.

SANTOS, V. B. M. P. (1996). Padrões interpessoais no gênero de cartas de negociação. Dissertação de Mestrado, LAEL - PUCSP.

SHIMAZUMI, M. (1996). The Knower and the Informant in Institutional Talk: A Transitivity Perspective. Dissertação de Mestrado, University of Liverpool.

SOUZA, S. M. P. (1997). A organização da mensagem em anúncios e cartas de pedido de emprego: um estudo transcultural. Tese de Doutoramento, LAEL - PUCSP.

STUBBS, M. (1996). Text and corpus analysis. London: Blackwell.

SWALES, J. M. (1990). Genre analysis - English in academic and research settings. Cambridge : Cambridge University Press.

THOMPSON, G. (1996). Introducing functional grammar. London: Edward Arnold.

THOMPSON, G. (1998). Resonance in text. In A. SÁNCHEZ-MACARRO e R. CARTER (eds.) Linguistic choice across genres: variation in spoken and written English. Amsterdam: John Benjamin.

THOMPSON, G. e THETELA, P. (1995). The sound of one hand clapping: the management of interaction in written discourse. Text, 15(1), p.103-127.

VAN NUS, M. (1999). Can we count on your booking of potatoes to Madeira- corporate context and discourse practices in direct sales letters. In BARGIELA-CHIAPPINI, F. e NICKERSON, C. (eds.) Writing business: genres, media and discourses. Pearson Education Limited. 